\title{
Comparison of body mass index and waist circumference of patients with and without nonalcoholic fatty liver in Tehran
}

\author{
Mahshid Akbari $^{1}$, Sima Zohari-Anboohi ${ }^{*}{ }^{\circledR}$, Ziba Borzabadi-Farahani ${ }^{3}$, Maliheh Nasiri $^{4}$, Taraneh Esteki $^{5}$ \\ ${ }^{1}$ Student Research Committee, School of Nursing and Midwifery, Shahid Beheshti University of Medical Science, Tehran, Iran \\ ${ }^{2}$ Department of Nursing/ Department of Midwifery and Reproductive Health, School of Nursing and Midwifery, Shahid \\ Beheshti University of Medical Science, Tehran, Iran \\ ${ }^{3}$ Department of Nursing/ Department of Midwifery and Reproductive Health School of Nursing and Midwifery, Shahid \\ Beheshti University of Medical Science, Tehran, Iran \\ ${ }^{4}$ Department of Biostatistics School of Nursing and Midwifery, Shahid Beheshti University of Medical Science, Tehran, Iran \\ ${ }^{5}$ Department of Basic Science school of Nursing and Midwifery, Shahid Beheshti University of Medical Science, Tehran, Iran
}

\section{*Correspondence to}

Sima Zohari-Anboohi, Email:

Simazohari@gmail.com

Received 10 May 2018 Accepted 28 July 2018 Published online 17 August 2018

Keywords: Non-alcoholic fatty liver, Lifestyle, Waist circumference, Body mass index

\section{Abstract}

Introduction: One of the most common forms of chronic liver disease related to lifestyle is nonalcoholic liver disease.

Objectives: The present study was conducted to compare weight and waist circumference of patients with and without non-alcoholic fatty liver disease (NAFLD) referred to hospitals affiliated to Tehran University of Medical Sciences in 2017.

Patients and Methods: This case-control study was carried out on 300 outpatients and inpatients patients aged between 18 to 65 years referred to the ultrasonography section of hospitals with convenience sampling method. Based on the results of ultrasonography, these subjects were divided into two groups; case (100 patients) and control group (200 subjects).

Results: The mean BMI (body mass index) and waist circumferences of patients without NAFLD were $22.47 \pm 1.97 \mathrm{~kg} / \mathrm{m}^{2}$ and $83.84 \pm 8.68 \mathrm{~cm}$, respectively, while in the patients with fatty liver the mean $\mathrm{BMI}$ and waist circumference were $26.10 \pm 2.21 \mathrm{~kg} / \mathrm{m}^{2}$ and $98.83 \pm 7.28 \mathrm{~cm}$, respectively $(P=0.001)$. Conclusion: The results of the data analysis showed that the patients with fatty liver have high levels of BMI in comparison with those who had not fatty liver. Regarding the high prevalence of nonalcoholic fatty liver, lifestyle changes and the implementation of educational interventions to increase awareness are necessary.

\section{Introduction}

One of the most common forms of chronic liver disease is the non-alcoholic fatty liver disease (NAFLD) in the world, and it is one of the main causes of hepatitis clinic visits in adults (1). The disease begins with a wide range of simple liver steatosis and can be converted to non-alcoholic steatohepatitis (NASH), fibrosis, cirrhosis, failure, and even liver cancer (2). Non-alcoholic liver disease indicates a range of clinical and pathological conditions that are characterized by macroscopic steatosis in the absence of alcohol consumption and include a range of simple steatosis to liver diseases such as NASH, fibrosis, cirrhosis and ultimately hepatocellular cancers (3).

The prevalence of NAFLD is 2-3 times

\begin{abstract}
Key point
Regarding the high prevalence of nonalcoholic fatty liver, lifestyle changes and the implementation of educational interventions to increase awareness and improve the attitude of individuals and design appropriate studies for the prevention and treatment of fatty liver are necessary.
\end{abstract}

higher compared to the hepatitis B and C and alcohol-related liver disease. NAFLD is now the most common cause of liver test disorder (4). In Asia, the prevalence of this disease varies between $12 \%$ to $24 \%$ by age, gender, place of residence and race. Recent studies in eastern countries have shown that their prevalence is increasing due to changes of lifestyle (high-fat diet, low physical

Copyright (C) 2018 The Author(s); Published by Nickan Research Institute. This is an open-access article distributed under the terms of the Creative Commons Attribution License (http://creativecommons.org/licenses/by/4.0), which permits unrestricted use, distribution, and reproduction in any medium, provided the original work is properly cited. 
activity, central obesity and type II diabetes mellitus). The prevalence of liver steatosis is estimated about $16 \%$ to $30 \%$ in the general population, which is comparable to western countries (5).

NAFLD is a multidimensional disease that is associated with a range of factors including genetics and lifestyle such as type of nutrition and physical activity (6). For this reason, treatment of this disease is mainly focused on behavioral and lifestyle interventions such as diet, increased physical activity and weight loss. However, according to recent studies in Iran, the rate of physical activity has been decreasing over the last decade (7), and the rate of obesity and overweight among Iranian men and women is significant (8).

\section{Objectives}

Considering the above mentioned, as well as increasing unhealthy diets and increasing use of fast foods, this study was conducted to evaluate the comparison of BMI (body mass index) and waist circumference in patients with and without non-alcoholic fatty liver (NAFLD) in Tehran University of Medical Sciences hospitals.

\section{Patients and Methods \\ Study population}

This case-control study was conducted on patients with and without NAFLD referred to hospitals affiliated to Tehran University of Medical Sciences. The case group was selected from outpatients and inpatients patients aged between 18 to 65 years old referred to the ultrasound section of selected hospitals, who had positive fatty liver disease. Control subjects were also selected from those who had a negative NAFLD. The inclusion criteria were willingness to participate in the study, outpatients and inpatients patients aged between 18 to 65, lack of experience with alcohol, lack of hepatitis B, C, liver cancer, Cushing's syndrome, chronic pancreatitis, Wilson's disease and thyroid disease. In this research, convenience sampling method was used. In this way, the samples were selected from people who were accessible to the scientist and divided into two groups of case and control. A group matching was applied to select the control group. The control group was matched in terms of age, gender distribution, distribution of education, occupation, marital status, place of residence, tobacco use and health insurance.

The minimum sample size was calculated 84. Considering the possible attrition, 100 cases and 200 controls were selected. The highest proportion of samples were selected from Imam Hossein hospital (82 subjects), and then from Taleghani hospital (70 subjects), Shohada hospital, Tajrish hospital (65 subjects), Imam Khomeini hospital (42 subjects) and Shariati hospital (41 subjects), respectively. The data collection was carried out through a demographic data collection form was presented as a self-administrated form, which includes the individual characteristics of the units studied including age, gender, height, weight, weight gain over the past year, waist circumference, occupational status, marital status, duration of NAFLD and medications. Waist circumference measured using an elastic 100-centimeters tape measuring at the lowest point (between the lower end of the chest and navel).

\section{Ethical considerations}

This research was conducted following the Declaration of Helsinki principles. Informed written consent was obtained from each patient. All data about individuals kept confidential. This study was approved by Ethics Committee of Shahid Beheshti University of Medical Science (\# IR.SBMU.RETECH.REC.1395.130).

\section{Statistical analysis}

The data were analyzed using SPSS 21 software, descriptive (mean, standard deviations and frequency) as well as independent $t$ test to compare the mean. Additionally, $P$ values of less than 0.05 were considered statistically significant.

\section{Results}

This study was conducted with the participation of 300 patients aged between 18 and 65years where 204 subjects were males (82 patients with fatty liver and 122 without fatty liver) and 94 subjects were females (18 with fatty liver and 78 without fatty liver). The mean age of subjects with fatty liver was $46.33 \pm 5.39$ years and average age of subjects without fatty liver was $47.20 \pm 7.96$ years. Most of research participants were married (84\%), job without physical activity (69\%) and no medication (84.5\%) (Table 1).

In Tables 2 and 3, the mean and standard deviation of waist circumference and BMI of patients was presented. There was a significant difference between the case and control group in terms of waist circumference and BMI respectively $(P=0.001)$, which means that the case group had a worse condition than the control group.

\section{Discussion}

The results of the study with the participation of 300 patients aged between 18 to 65 years old, which 204 were male (82 subjects had had fatty liver and 122 subjects had not fatty liver) and 94 subjects were women (18 subjects had fatty liver and 78 subjects had not fatty liver). The mean age of subjects with fatty liver was $46.33 \pm 4.39$ years and the mean age of other group was $47.20 \pm 7.96$ years. The mean BMI in the fatty liver group was $26.10 \pm 1.22 \mathrm{~kg} /$ $\mathrm{m}^{2}$ and $22.47 \pm 1.97 \mathrm{~kg} / \mathrm{m}^{2}$, respectively. The mean waist circumference of fatty liver group was $98.83 \pm 7.28 \mathrm{~cm}$ and in the other group was $84.83 \pm 8.68 \mathrm{~cm}$. Most of research participants were married (84\%), job without physical activity (69\%) and no medication (84.5\%).

The mean of BMI and waist circumference of patients without fatty liver was lower than those with fatty liver, which was also statistically significant. In terms of BMI and waist circumference, the results of study by HusseinPanah et al, was conducted on the role of predictive variables of non-alcoholic fatty liver in patients with type 
Table 1. Descriptive characteristics of gender, marital status, medication, job, age, waist circumference, and BMI and comparing them in research groups

\begin{tabular}{|c|c|c|c|c|}
\hline Variable & Level & Healthy, No. (\%) & Fatty liver, No. (\%) & $P$ value \\
\hline \multirow{2}{*}{ Gender } & Male & $122(61)$ & $82(82)$ & \multirow{2}{*}{0.001} \\
\hline & Female & $78(39)$ & $18(18)$ & \\
\hline \multirow{4}{*}{ Marital status } & Single & $34(17)$ & $5(5)$ & \multirow{4}{*}{0.001} \\
\hline & Married & $138(69)$ & $84(84)$ & \\
\hline & Divorced & $20(10)$ & $6(6)$ & \\
\hline & Died & $8(4)$ & $5(5)$ & \\
\hline \multirow{2}{*}{ Medication } & Yes & $31(15.5)$ & $73(73)$ & \multirow{2}{*}{0.001} \\
\hline & No & $169(84.5)$ & $27(27)$ & \\
\hline \multirow{2}{*}{ Job } & With physical activity & $127(63.5)$ & $31(31)$ & \multirow{2}{*}{0.001} \\
\hline & Without physical activity & $73(36.5)$ & $69(69)$ & \\
\hline
\end{tabular}

Table 2. Comparison of waist circumference in the two case and control groups

\begin{tabular}{lccc}
\hline Variable & Groups & Mean & Standard Deviation \\
\hline \multirow{2}{*}{ Waist circumference $(\mathrm{cm})$} & Healthy & 83.84 & 8.68 \\
& Fatty liver & 98.83 & 7.28 \\
\hline
\end{tabular}

Table 3. Comparison of BMI in the two case and control groups

\begin{tabular}{|c|c|c|c|c|}
\hline Variable & Groups & Mean & Standard Deviation & $P$ value \\
\hline \multirow{2}{*}{$\mathrm{BMI}\left(\mathrm{kg} / \mathrm{m}^{2}\right)$} & Healthy & 22.47 & 1.97 & \multirow{2}{*}{0.001} \\
\hline & Fatty liver & 26.10 & 2.21 & \\
\hline
\end{tabular}

2 diabetes, showed that the mean waist circumference and BMI in healthy subjects were equal to 94 and 24.8 (9).

Moradi Kohanki et al reported that BMI for healthy subjects was $24.9 \mathrm{~kg} / \mathrm{m}^{2}$, while most healthy people in this study were in the mean age of 47.20 years and had an appropriate BMI. The BMI for people aged 45-64 was $25 \mathrm{~kg} / \mathrm{m}^{2}$, hence BMI more than $25 \mathrm{Kg} / \mathrm{m}^{2}$ indicates overweight in individuals (10). In the study of Pavlica et al., the waist circumference and BMI were $82.71 \mathrm{~cm}$ and $23.5 \mathrm{~cm}$, respectively. The mean age of healthy subjects in their study was 37.36 years, which was appropriate for their mean BMI (11).

There are many studies about the physical and occupational index of people with fatty liver, which confirm these results. In the study by Moradi Kohnaki et al., people with fatty liver had a BMI greater than $25 \mathrm{~kg} / \mathrm{m}^{2}$. People who participated in their research were in the age group of 3039 and 40-49 years. The waist circumference of patients with fatty liver in the study of Moradi Kohnaki et al was about $102 \mathrm{~cm}$ in men and $88 \mathrm{~cm}$ in women (10). Recently, Safarpour et al compared the anthropometric indices in patients with non-alcoholic fatty liver with healthy people. The waist circumference in the patient was equal to 101.8 $\mathrm{cm}$. In the present study, it was equal to $98.3 \mathrm{~cm}$ for people with fatty liver.

In their study, the BMI for people with fatty liver was 28.6 $\mathrm{kg} / \mathrm{m}^{2}$, while the mean age of their participants in the study was 41.3 years, which should be equal to 24 for this age (12). In the study of Younesian et al, the mean BMI for students with fatty liver problems was $31.66 \mathrm{~kg} / \mathrm{m}^{2}$ and the mean waist to hip ratio was equal to 0.96 (13).

The mean BMI of patients without fatty liver was is 22.47 $\mathrm{Kg} / \mathrm{m}^{2}$, which was $26.10 \mathrm{~kg} / \mathrm{m}^{2}$ for patients with fatty liver. According to the mean age of the non-affected group (47.20 years) and those with fatty liver ( 46.34 years), it was shown that non-affected people have a more normal body mass than those with fatty liver. The results of researches such as Khoshbaten et al and Moradi Kohnaki et al showed that the high mean BMI and mean waist circumference in people increase their chances of developing fatty liver disease $(11,14)$

As mentioned by Moradi Kohnaki et al, waist circumference and BMI can grossly predict the development of fatty liver. The results of a study in Japan showed that BMI was an appropriate predictor for the onset of NAFLD in both genders. The odds ratio for fatty liver in overweight individuals and obese people was 1.8 and was 5.33 respectively. Overweight and obese people are in the risk of fatty liver by 4.01 and 7. 28, respectively with one-unit increment of BMI (15).

\section{Conclusion}

Regarding the high prevalence of non-alcoholic fatty liver, lifestyle changes and the implementation of educational interventions to increase awareness and improve the attitude of individuals and design appropriate studies for the prevention and treatment of fatty liver are necessary. People with fatty liver, should consider changes in dietary 
habits and physical activity.

\section{Limitations of the study}

The relatively small sample size was a limitation of this study.

\section{Acknowledgments}

The researcher appreciates the Deputy of Research of Shahid Beheshti University of Medical Sciences and Tehran University of Medical Sciences for cooperation in data collection and patients who participated in this study.

\section{Authors' contribution}

MA and SZ participated in research design, the writing of the paper, and the performance of the research. $\mathrm{ZB}$ and $\mathrm{MN}$ contributed to the study design, preparation of the manuscript and final revision. TE acted as consultant of study. All authors read and approved the paper.

\section{Conflicts of interest}

The authors declare no conflict of interest.

Ethical considerations

Ethical issues (including plagiarism, data fabrication, double publication) have been completely observed by the authors.

\section{Funding/Support}

This study was taken from master's thesis with the code of ethics of IR.SBMU RETECH.REC.1395.130.

\section{References}

1. Krasnoff JB, Painter PL, Wallace JP, Bass NM, Merriman RB. Health-related fitness and physical activity in patients with nonalcoholic fatty liver disease. Hepatology. 2008;47:115866. doi: 10.1002/hep.22137.

2. Nikroo H, Mohammadian M, Nematy M, Sima HR, Attarzadeh Hosseini SR. The effect of diet and exercise on improvement of quality of life in patients with nonalcoholic steatohepatitis. J Kerman Univ Med Sci. 2015;22:61-72.

3. Ma X, Hua J, Li Z. Probiotics improve high fat diet-induced hepatic steatosis and insulin resistance by increasing hepatic NKT cells. J Hepatol. 2008;49:821-30. doi: 10.1016/j. jhep.2008.05.025.

4. Williams CD, Stengel J, Asike MI, Torres DM, Shaw J, Contreras $\mathrm{M}$, et al. Prevalence of nonalcoholic fatty liver disease and nonalcoholic steatohepatitis among a largely middle-aged population utilizing ultrasound and liver biopsy: a prospective study. Gastroenterology. 2011;140:124-31. doi: 10.1053/j. gastro.2010.09.038.

5. Harrison SA, Day CP. Benefits of lifestyle modification in NAFLD. Gut. 2009;56:1760-9. doi: 10.1136/gut.2006.112094.

6. Nseir W, Hellou E, Assy N. Role of diet and lifestyle changes in nonalcoholic fatty liver disease. World J Gastroenterol. 2014;20:9338-44. doi: 10.3748/wjg.v20.i28.9338.

7. Koohpayehzadeh J, Etemad K, Abbasi M, Meysamie A, Sheikhbahaei S, Asgari F, et al. Gender-specific changes in physical activity pattern in Iran: national surveillance of risk factors of non-communicable diseases (2007-2011). Int J Public Health. 2014;59:231-41. doi: 10.1007/s00038-0130529-3.

8. Moghimi-Dehkordi B, Safaee A, Vahedi M, Pourhoseingholi MA, Pourhoseingholi A, Zali MR, et al. The prevalence of obesity and its associated Demographic Factors in Tehran, Iran. J Health Develop. 2012;1:22-30.

9. Hossein-Panah F, Sadeghi L, Rambod M, Foroutan M, Naseri M. Assessing predicting factors in non-alcoholic fatty liver disease (NAFLD) in type 2 diabetes. Pejouhesh. 2006;30:9-15.

10. Moradi Kohnaki Z, Asadollahi K, Abangah G, Sayehmiri K. Risk factors of nonalcoholic fatty liver disease: a case-control study. Tehran Univ Med J. 2016;74:645-656.

11. Pavlica T, Bozic-Krstic V, Rakic R. Body mass index, waist-tohip ratio and waist/height in adult population from Backa and Banat-the Republic of Serbia. Ann Hum Biol. 2010;37:56273. doi: 10.3109/03014460903512829.

12. Safarpor M, Kohan L, Porkhajeh A. Comparative study of anthropometric parameters in non-alcoholic fatty liver disease patients and healthy subjects. J Sabzevar Univ Med Sci. 2015;22:225-231

13. Younesian A, Moradi H, Razavianzade N, Zahedi E. Prevalence of fatty liver using ultrasound in male high-school pupils without history of liver disease and its relationship with liver enzymes, body mass index and waist-hip ratio. Razi J Med Sci. 2015;22:79-86.

14. Khoshbaten M, Fatahi E, Soomi MH, Tarzmani MK, Farhang S, Majidi G, et al. Clinico- biochemical comparison of patients with Nonalcoholic fatty liver disease and healthy populace. Zahedan J Research Med Sci. 2009;11:13-21.

15. Miyake $T$, Kumagi $T$, Hirooka $M$, Furukawa $S$, Koizum $M$, Tokumoto $Y$, et al. Body mass index is the most useful predictive factor for the onset of nonalcoholic fatty liver disease: a community-based retrospective longitudinal cohort study. J Gastroenterol. 2013;48:413-22. doi: 10.1007/s00535012-0650-8. 